\title{
Posisi Republik Islam Iran Dalam Program Nuklir Dalam Perspektif Amerika Serikat
}

\author{
Hendra Maujana Saragih, Mega Murti Lestari, Nurmaida Muis \\ Universitas Nasional, Jakarta \\ hendramaujana@gmail.com
}

\begin{abstract}
Abtract
Iran is one of the countries that developed nuclear with the aim of developing energy and has agreed on a Joint Comprehensive Plan of Action (JCPOA) agreement with the United States and other countries. This agreement contains about Iran's willingness to limit its nuclear but 3 years later Trump came out unilaterally from the agreement because he thought Iran was trying to develop technology to make weapons of mass destruction. The attitude of the United States in dealing with Iran's nuclear program in which during the administration of Donald Trump, Trump refused Iran to develop its nuclear because Iran can make nuclear weapons and pose a threat to peace in the world, especially the Middle East region. Using qualitative methods to describe the US foreign policy towards Iran. This is done by the United States solely to maintain security in the world, especially security stability in the Middle East region, where the use of nuclear weapons can be very dangerous if done without security regulations. Trump imposed a new foreign policy on Iran by applying maximum pressure to pressure Iran to negotiate a new nuclear agreement.
\end{abstract}

Key Words: United States, Donald Trump, Iran Nuclear, Foreign Policy, JCPOA,

\begin{abstract}
Abstrak
Iran adalah salah satu negara yang mengembangkan nuklir dengan tujuan pengembangan energi dan telah menyepakati perjanjian Joint Comprehensive Plan of Action (JCPOA) bersama Amerika Serikat dan negara lainnya. Perjanjian ini berisi tentang kesediaan Iran untuk membatasi nuklirnya tetapi 3 tahun kemudian Trump keluar secara sepihak dari perjanjian tersebut karena menganggap Iran berusaha mengembangkan teknologi untuk membuat senjata pemusnah massal. Sikap Amerika Serikat dalam menangani program nuklir Iran dimana pada masa pemerintahan Donald Trump, Trump menolak Iran mengembangkan nuklirnya karena Iran
\end{abstract}

FOKUS : Jurnal Kajian Keislaman dan Kemasyarakatan Vol. 5, No. 1, 2020

LPPM Institut Agama Islam Negeri (IAIN) Curup - Bengkulu

p-ISSN 2548-334X, e-ISSN 2548-3358

DOI: $10.29240 /$ jf.v5i1.1365 
dapat membuat senjata nuklir dan menjadi ancaman bagi perdamaian di dunia, khususnya kawasan Timur Tengah. Dengan menggunakan metode kualitatif untuk mendeskripsikan kebijakan luar negeri Amerika Serikat terhadap Iran. Hal dilakukan Amerika Serikat semata - mata untuk menjaga keamanan di dunia khususnya stabilitas keamanan di kawasan Timur Tengah, dimana penggunaan nuklir dapat sangat berbahaya jika dilakukan tanpa adanya peraturan keamanan. Trump memberlakukan kebijakan luar negeri yang baru terhadap Iran dengan menerapkan maximum pressure untuk menekan Iran melakukan negosiasi dengan membuat kesepakatan nuklir yang baru.

Kata Kunci: Amerika Serikat, Donald Trump, Nuklir Iran, Kebijakan luar negeri, JCPOA

\section{Pendahuluan}

Setelah berakhirnya perang dingin antara dua negara adidaya memberikan efek kepada negara - negara lain untuk memiliki senjata nuklir yang dilatar belakangi oleh keamanan negara ataupun meningkatkan pengaruh negara. Iran adalah salah satu negara yang mengembangkan nuklir dengan tujuan pengembangan energi. ${ }^{1}$ Dimana sejak masa pemerintahan Shah Mohammad Reza Pahlevi, Iran telah melakukan perjanjian kerjasama dengan Amerika Serikat dalam penggunaan energi untuk memajukan program nuklir Iran dan Amerika Serikat akan memberikan Iran teknologi reaktor nuklir atau melalui program "Atoms for Peace". 2

Program tersebut sebelumnya disampaikan Eisenhower saat berpidato dalam Majelis Umum Perserikatan Bangsa-Bangsa (PBB) pada Desember 1953 dan menjadi dasar perjanjian nuklir Iran dengan Amerika Serikat. ${ }^{3}$ Program nuklir Iran dibentuk untuk menjaga kekuatan dan keamanan Amerika Serikat dari nasionalisme Arab dan Negara-negara Arab yang prosoviet. ${ }^{4}$

Pada tahun 1970an Iran bergabung dalam Non Proliferation Treaty (NPT) dan membentuk Atomic Energy Organization of Iran (AEOI) pada

\footnotetext{
${ }^{1}$ Rio Sundari, Strategi Amerika Serikat Dalam Menekan Pengembangan Nuklir Iran, Jurnal Vol 1 No 2, 2019, hal 215

${ }^{2}$ Fahimeh Behrang, U.S Foreign Policy Interests and Iran's Nuclear Program, tesis, Canada, University of Saskatchewan, 2012, hal. 12

${ }^{3}$ Ibid.

${ }^{4}$ Ibid, hal. 13
} 
tahun $1974 .{ }^{5}$ Pengembangan program nuklir damai Iran didasarkan pada pasal 4 NPT yang berisi : ${ }^{6}$

"Semua Negara di dunia berhak memanfaatkan tenaga nuklir secara damai dan wajib melaporkan semua kegiatan yang terkait program nuklirnya kepada International Atomic Energy Agency"

Setelah terjadinya revolusi Islam di Iran pada tahun 1979, membuat hubungan Amerika Serikat dengan Iran memburuk. Kerjasama program nuklir Iran pasca jatuhnya pemerintahan Shah di Iran berubah menjadi konflik. Amerika Serikat tidak lagi membantu program nuklir Iran dikarenakan telah ditemukannya pengayaan uranium bawah tanah di Natanz dan Esfahan. ${ }^{7}$ Setelah itu, Amerika Serikat membekukan aset Iran senilai \$10 Miliar dan memblokir semua kerjasama yang pernah dilakukan sebelumnya dengan Iran. ${ }^{8}$ Amerika Serikat juga menangguhkan kerjasama program nuklir dengan Iran.

Pada 12 September 2003, The International Atomic Energy Agency (IAEA) mengadopsi resolusi yang menyerukan Iran untuk menunda semua kegiatan pengayaan, lalu pada maret 2007 DK PBB mengadopsi Resolusi 1747 sebagai tanggapan atas kegagalan iran untuk memenuhi permintaan dewan untuk menunda pengayaan uranium, lalu pada 2010 Iran memulai proses memproduksi uranium yang diperkaya 20\% dan DK PBB mengadopsi resolusi 1929 untuk melarang Iran melakukan tes rudal balistik, ${ }^{9}$ dan

\footnotetext{
${ }^{5}$ BBC News, Iran nuclear crisis in 300 words, September 2019. https://www.bbc.com/news/world-middle-east-48201138, diakses 4 September 2019

${ }^{6}$ Resty Meiva Rizky, Perubahan Kebijakan Nuklir Iran Di Era Pemerintahan Hassan Rouhani, Jurnal Mahasiswa Bidang Ilmu Sosial dan Ilmu Politik 2, Riau, Universitas Riau, 2013, hal. 6

${ }^{7}$ Anthony H. Cordesman dan Khalid R. Al-Rodhan, Iranian Nuclear Weapons? The Uncertain Nature of Iran's Nuclear Programs, Center for Strategic and International Studies, 2006, hal. 13.

https://csis-prod.s3.amazonaws.com/s3fspublic/legacy_files/files/media/csis/pubs/060412_iran_uncertainty.pdf, diakses 4 September 2019

${ }^{8}$ Fahimeh Behrang, Op. Cit., hal. 21 Of Nuclear Diplomacy With Iran,https://www.armscontrol.org./factsheets/Timeline-Of-Nuclear-Diplomacy-WithIran\#2010, diakses 1 juni 2020
} 
melakukan embargo yaitu melarang Uni Eropa untuk mengimpor minyak dari Iran dan bergabung dengan Amerika Serikat. ${ }^{10}$

Hubungan Amerika Serikat dan Iran terus bermusuhan karena Iran dipandang sebagai ancaman yang kuat. Bill Clinton, presiden Amerika Serikat selanjutnya melarang perusahaan asing Amerika Serikat di Iran untuk melakukan investasi dan transaksi perdagangan dengan Iran. ${ }^{11}$ Namun, Iran tetap mengembangkan kemampuan nuklirnya walaupun mendapat kecaman dan sanksi dari Amerika Serikat.

Sebagai salah satu kekuatan hegemoni di dunia khususnya di Kawasan Timur Tengah, Amerika Serikat menjadi salah satu Negara yang menjadi pelopor dalam menentang program nuklir Iran. Presiden Bush menganggap Iran sebagai "Rogue State" karena sikapnya yang bertentangan dengan kepentingan Amerika Serikat. ${ }^{12}$ Selain itu, Bush dalam pidatonya juga menganggap Iran bersama Irak dan Korea Utara sebagai "Axis of Evil". Bush menyebutkan bahwa Iran adalah salah satu negara yang akan mengancam perdamaian dunia.

Ketika Barack Obama menjabat sebagai Presiden Amerika Serikat, Obama menggunakan soft diplomacy guna mencegah perluasan program nuklir Iran dengan mendorong Iran untuk terlibat dalam dialog terkait program nuklirnya. Pada tahun 2013, Hassan Rouhani terpilih sebagai Presiden Iran yang dianggap sebagai politisi yang lebih moderat dan pragmatis. Rouhani juga lebih mengutamakan melakukan negosiasi terkait solusi program nuklirnya guna mengakhiri embargo yang dialami Iran.

Amerika Serikat dan Iran akhirnya menyepakati perjanjian Joint Comprehensive Plan of Action (JCPOA) atau yang disingkat P5+1 pada tahun 2015 di Wina bersama dengan Negara Tiongkok, Perancis, Jerman, Rusia, Inggris serta Uni Eropa atau yang disingkat dengan P5+1. ${ }^{13}$ Perjanjian ini berisi tentang kesediaan Iran untuk membatasi nuklirnya dengan imbalan

\footnotetext{
${ }^{10}$ Resty Meiva Rizky, Op. Cit, hal 3

${ }^{11}$ Ibid, hal. 27-28

${ }^{12}$ Ibid, hal. 30

${ }^{13}$ Noviyanti, Polemik Perubahan Kebijakan Amerika Serikat dalam Kesepakatan The Joint Comprehensive Plan of Action (JCPOA) Nuklir Iran, LIPI, 2019.http://www.politik.lipi.go.id/kolom/kolom-1/politik-internasional/1288-polemikperubahan-kebijakan-amerika-serikat-dalam-kesepakatan-the-joint-comprehensvie-plan-ofaction-jcpoa-nuklir-iran, diakses 4 September 2019
} 
dicabutnya sanksi ekonomi yang diberikan oleh Iran. ${ }^{14}$ Iran setuju untuk membatasi program nuklirnya dengan mengurangi persediaan uranium yang ada sebesar 98 persen, pengurangan ini akan berlangsung selama 15 tahun, dan Iran akan dibatasi untuk memperkaya uranium sebesar 3,67 persen. ${ }^{15}$ Selain itu, semua aktivitas nuklir Iran akan dipantau oleh IAEA dengan memberi kewenangan untuk menggunakan teknologi pemantauan yang canggih.

Dalam melakukan penelitian tentang kebijakan Amerika Serikat terhadap Nuklir Iran pada masa pemerintahan Donald Trump Periode 20182019 terdapat beberapa literatur yang membahas tentang penelitian serupa.Rujukan pertama adalah penelitian dariMohammaed Cherkaouiyang berjudul "Trump's Withdrawal form the Iran Nuclear Deal: Security or Economics?"menjelaskan bahwa Amerika Serikat memberikan sanksi ekonomi tambahan terhadap Iran pasca keputusan Trump untuk keluar dari perjanjian nuklir Iran. Trump memfokuskan 3 poin penting yang saling berhubungan antara keamanan dan ekonomi Iran, yakni mencegah rezim Iran yang dianggap sebagai sponsor utama teror di kawasan Timur Tengah dengan memperkaya uranium dan mencapai program nuklirnya, menjatuhkan sanksi ekonomi yang tertinggi terhadap Iran dan memberikan sanksi kepada Negara manapun yang membantu Iran dalam mengembangkan program nuklirnya, dan menjadikan aset Iran sebagai aset beku.

Trump memenuhi janjinya pada saat kampanye untuk memisahkan diri dari kesepakatan nuklir dengan Iran yang diinisiasi oleh Presiden Amerika Serikat sebelumnya, Barack Obama. Cherkaoui menjelaskan bahwa hal ini kemudian membuat kebijakan baru Amerika Serikat untuk menjadi pemimpin yang anti - obama. Keluarnya Amerika Serikat dari perjanjian nuklir Iran menjadi inti dari proteksionisme Trump.

Penelitian selanjutnya dari Robert Einhorn dan Richard Nephew yang berjudul "Constraining Iran's Future Nuclear Capabilities". Dalam

${ }^{14}$ A Croft, Iran Nuclear Talks Show Progress, Western Diplomat Says, Reuters, 2013. https://www.reuters.com/article/us-iran-nuclear-talks/iran-nuclear-talks-constructivewestern-diplomat-says-idUSBRE91R1IO20130228, diakses 4 September 2019

${ }^{15}$ Milena Sterio, President Obama's Legacy: The Iran Nuclear Agreement, Case Western Reserve Journal of International Law Vol. 48, 2016, hal. 74-75, https://scholarlycommons.law.case.edu/cgi/viewcontent.cgi?article=2236\&context=jil, diakses 5 September 2019 
penelitian tersebut, Amerika Serikat membutuhkan strategi baru untuk membatasi masa depan pengembangan nuklir Iran. Penelitian ini berpendapat bahwa Amerika Serikat perlu melakukan perundingan nuklir baru dengan Iran yang dibangun dengan dasar yang kuat dari sebelumnya.

Presiden sebelumnya Barack Obama menganggap kesepakatan tersebut adalah langkah yang efektif dalam memblokir Iran untuk pengembangan senjata nuklir dan sebagai platform dalam mencapai solusi nuklir Iran di masa depan. Trump menentang JCPOA karena menganggap bahwa kesepakatan tersebut memiliki banyak kekurangan dan gagal untuk menangani aspek - aspek lain dari perilaku Iran seperti program rudal Iran dan kegiatan regionalnya.

Trump berharap bahwa tekanan yang diberikan Amerika Serikat dapat memaksa Iran untuk menerima kesepakatan baru yang komprehensif. Kesepakatan yang tidak hanya berisi pembatasan nuklir tetapi juga tentang kegiatan Iran dalam mendukung rezim Suriah. Perselisihan antara Amerika Serikat dan Iran saat ini tidak ditemukan jalan keluarnya. Tekanan ekonomi yang diberikan oleh Amerika Serikat tidak membuat Iran menyerah untuk merevisi kesepakatan nuklirnya. Strategi tersebut dilakukan agar Iran dapat menerima batasan nuklir yang lebih ketat dan membatasi perilakunya ke Negara lain.

Amerika Serikat berusaha mencegah tiga tahap aktivitas Iran yang mengancamnya, yakni mencegah permulaan program nuklir Iran dari JCPOA, mencegah pengembangan nuklir Iran, dan mencegah Iran memperkaya uraniumnya dengan berlebihan atau dalam membuat senjata nuklir. Trump melakukan sanksi, tindakan kontra - proliferasi dan pencegahan terhadap Iran untuk menekan Iran dalam mengembangkan kemampuan nuklirnya. Trump berpendapat bahwa langkahnya untuk menarik diri dari JCPOA adalah upaya untuk mencapai solusi yang efektif dengan membuat kesepakatan nuklir yang baru.

Hubungan Amerika Serikat dan Iran selalu mengalami pasang surut dan dinamis. Seiring dengan bergantinya kepemimpinan Amerika Serikat, Presiden Trump membatalkan perjanjian tersebut dan keluar secara sepihak pada tanggal 8 Mei 2018. ${ }^{16}$ Trump merasa perjanjian tersebut hanya akan

\footnotetext{
${ }^{16}$ Noviyanti,Loc.Cit.
} 
membuat keresahan dan tidak akan membawa ketenangan bagi Kawasan Timur Tengah khususnya bagi Amerika Serikat. Amerika Serikat menganggap bahwa Iran berusaha mengembangkan teknologi untuk membuat senjata pemusnah massal.

Pasca keluar dari perjanjian tersebut, Amerika Serikat memberikan tekanan kepada Iran berupa sanksi ekonomi dan tekanan politik. ${ }^{17}$ Sanksi ekonomi yang diberlakukan Amerika Serikat dapat memukul perekonomian Iran. Hal ini dikarenakan Amerika Serikat memberikan sanksi ekonomi berupa pembatasan Iran untuk mengekspor minyak. Iran sangat bergantung pada ekspor minyak dan Amerika Serikat berharap sanksi tersebut membuat negara Iran terpuruk. Amerika Serikat akan terus memastikan untuk memblokir sumber daya yang dibutuhkan Iran sehingga tidak dapat untuk mengembangkan program nuklirnya. Selain itu, Amerika Serikat juga mengatakan ingin menghentikan apa yang disebutnya sebagai beragam kegiatan "jahat" yang dilakukan oleh Iran, termasuk serangan dunia maya, uji coba rudal balistik, dan dukungan terhadap kelompok teroris dan milisi di Timur Tengah. ${ }^{18}$

Iran mengatakan aktivitas nuklirnya sebagai hal yang sah karena demi pertahanan negaranya. Iran meminta dukungan kepada Negara-negara lain yang ikut perjanjian untuk memberikan kelonggaran ekonomi, khususnya Negara - negara yang mengekspor minyaknya. ${ }^{19}$ Iran juga membela bahwa masalah pengayaan uranium tidak melanggar pakta nonproliferasi dan Iran juga berhak akan itu. Semua aktivitas Iran dibawah pengawasan IAEA dan dengan cara yang transparan. Namun, dalam pidatonya di Gedung Putih, Presiden Trump tetap mengatakan Amerika Serikat tetap menolak seluruh aktivitas nuklir Iran dan tidak peduli terhadap respondan kecaman dari

${ }^{17}$ Adirini Pujayanti, Sengketa Nuklir Iran-Amerika Serikat, Puslit BKD, 2019, hal. 7,https://berkas.dpr.go.id/puslit/files/info_singkat/Info\%20Singkat-XI-10-II-P3DI-Mei2019-179.pdf, diakses 5 September 2019

${ }^{18}$ BBC News, Amerika Serikat terapkan 'sanksi terberat', apakah Iran bisa tumbang?, 5 November 2018, https://www.bbc.com/indonesia/dunia-46093285, diakses 5 September 2019

19 VOA, AS Siap Terapkan Sanksi Baru terhadap Iran, 24 Juni 2019, https://www.voaindonesia.com/a/as-terapkan-sanksi-baru-terhadap-iran/4971499.html, diakses 5 September 2019 
8 | FOKUS : Jurnal Kajian Keislaman dan Kemasyarakatan Vol. 5, No. 1, 2020

Negara - negara lain karena Amerika Serikat dianggap melanggar kesepakatan nuklir $2015 .^{20}$

Kebijakan Amerika Serikat dilakukan semata - mata untuk menjaga keamanan di dunia khususnya stabilitas keamanan di kawasan Timur Tengah. Dengan demikian, Presiden Trump menganggap perjanjian nuklir Iran merupakan kesepakatan terburuk yang pernah dibuat oleh Amerika Serikat. ${ }^{21}$ Dalam pidatonya, Trump berpendapat perjanjian tersebut akan merugikan Amerika Serikat dan memperlihatkan kelemahan dari Amerika Serikat. ${ }^{22}$ Amerika Serikat tidak akan mau melanjutkan hal yang nantinya akan menimbulkan kekerasan, terror, dan ancaman dari nuklir Iran. Kebijakan baru Trump adalah menjadi pemimpin yang anti - obama. ${ }^{23}$

Dalam pengambilan kebijakan, selain presiden yang memutuskan terdapat faktor lain berupa faktor domestik dan juga faktor internasional. Pengambilan kebijakan suatu Negara terhadap Negara lain akan sesuai dengan kepentingan nasional dari suatu Negara. Amerika Serikat dalam menanggapi isu nuklir Iran juga akan sesuai dengan tujuan nasional yang hendak untuk dicapai. Kebijakan Amerika Serikat pada masa pemerintahan Trump lebih mengedepankan pada hard power, yakni dengan memberikan tekanan kepada Iran agar sesuai dengan kepentingan Amerika Serikat.

Dengan menggunakan metode kualitatif dalam melakukan penelitian Kebijakan Luar Negeri Amerika Serikat terhadap pengembangan nuklir Iran Pada Masa Pemerintahan Donald Trump. Metode kualitatif digunakan untuk mendeskripsikan tentang dinamika hubungan Amerika Serikat dengan Iran dan juga mendeskripsikan kebijakan luar negeri Amerika Serikat terhadap Iran dalam hubungannya dengan pengembangan nuklir Iran saat Donald Trump berkuasa periode $2018-2019$.

Kepentingan nasional suatu negara dapat diwujudkan melalui perumusan kebijakan luar negeri. Kebijakan luar negeri merupakan

\footnotetext{
${ }^{20} \mathrm{Bbc}$, Loc.Cit.

${ }^{21}$ CNN, Polemik Pakta Nuklir Iran: Optimisme yang Terancam Kandas, 9 Mei 2019, https://www.cnnindonesia.com/internasional/20190509134640-120-393376/polemikpakta-nuklir-iran-optimisme-yang-terancam-kandas, diakses 5 September 2019

${ }^{22}$ DonaldJTrump.com, Donald Trump Foreign Policy Speech

${ }^{23}$ Mohammed Cherkaoui,Trump's Withdrawal from the Iran Nuclear Deal: Security or Economics, Aljazeera Centre for Studies, 2018, hal. 4, https://studies.aljazeera.net/sites/default/files/articles/reports/documents/d6a4c71882da438e 9de76152c7e3a8dc_100.pdf, diakses 5 September 2019
} 
kebijaksanaan suatu negara yang ditujukan ke negara lain untuk mencapai suatu kepentingan tertentu. Pada hakikatnya, kebijakan luar negeri merupakan suatu kebijakan, sikap atau respon terhadap lingkungan ekologisnya. Menurut Jack C. Plano dan Roy Olton kebijakan luar negeri merupakan suatu tindakan yang dibentuk oleh para pembuat keputusan (decision maker) suatu negara dalam menghadapi negara lain (state to state) atau unit politik internasional lainnya. Kebijakan luar negeri dikendalikan untuk mencapai tujuan nasional yang dituangkan dalam terminologi kepentingan nasional. ${ }^{24}$

Tujuan nasional yang hendak dijangkau melalui kebijakan luar negeri merupakan formulasi konkret dan dirancang dengan mengaitkan kepentingan nasional terhadap situasi internasional yang sedang berlangsung serta power yang dimiliki untuk menjangkaunya. ${ }^{25}$ Tujuan dirancang, ditetapkan, dan dipilih oleh pembuat keputusan dan dikendalikan untuk mengubah kebijakan (revisionist policy) atau mempertahankan kebijakan (status quo policy) dari negara tertentu di lingkungan internasional. ${ }^{26}$

\section{Kebijakan Luar Negeri Amerika Serikat dalam Program Nuklir Iran}

Sebagai negara adidaya politik luar negeri Amerika Serikat memiliki pengaruh yang besar di sistem internasional. Peran Amerika Serikat digambarkan sebagai kepemimpinan global, dimana Amerika Serikat cenderung menjadi negara pertama untuk mengidentifikasi atau menyelesaikan masalah internasional dan menegakkan aturan dan norma internasional. Hal ini menjelaskan bahwa Amerika Serikat mengejar kebijakan luar negeri untuk menjadi hegemoni di dunia. Sejak awal berdiri Amerika Serikat sudah mempunyai keinginan untuk menguasai dunia yang terdapat dalam manifest destiny, dimana para pembuat kebijakan Amerika Serikat dituntun dan dipengaruhi dalam mengambil sikap untuk menentukan pola kebijakan luar negeri. 1999), hal. 5

${ }^{24}$ J. C Plano dan R Olton, Kamus Hubungan Internasional, (Bandung: Abardin,

25 A. A Perwita dan Y. M Yani, Pengantar Ilmu Hubungan Internasional, (Bandung: Remaja Rosdakarya, 2005), hal. 51

${ }^{26}$ Plano dan Olton, op.cit, hal. 6 
Pelaksanaan kebijakan luar negeri Amerika Serikat didasari pada empat poin, yaitu ${ }^{27}$

1. Onward looking. Kebijakan luar negeri dibuat dengan memperhatikan peluang dan tantangan yang berasal dari luar negara Amerika.

2. Kebijakan luar negeri adalah tentang pilihan. Para pembuat kebijakan memiliki banyak pilihan yang terbuka dalam menentukan kebijakannya.

3. Kebijakan luar negeri dipengaruhi oleh pertimbangan domestik. Kebijakan yang diambil tidak hanya dipengaruhi oleh faktor eksternal, tetapi juga mempertimbangkan institusi dan masyarakat di dalamnya.

4. Kebijakan luar negeri dipengaruhi oleh masa lalu. Persepsi masa lalu menjadi pertimbangan para pembuat kebijakan untuk mengambil pilihan kebijakannya.

Dalam membentuk kebijakan luar negeri, presiden mendapat saran dari Dewan Keamanan Nasional yang terdiri dari wakil presiden, Menteri luar negeri, Menteri pertahanan, kepala Badan Intelijen Pusat (CIA) dan kepala staf gabungan militer. ${ }^{28}$

Presiden Amerika Serikat adalah kepala negara Amerika Serikat, kepala eksekutif pemerintah federal dan panglima Angkatan bersenjata. Dalam memilih presiden, Amerika Serikat hanya memiliki dua partai politik, yakni Partai Republik (konservatif) dan Partai Demokrat (liberal). Setiap presiden yang terpilih diharuskan untuk mempertahankan wilayah Amerika Serikat, mempertahankan keunggulan militer Amerika, memajukan perekonomian Amerika, mendukung dan mempertahankan nilai - nilai konstitusional, dan memberikan dukungan bagi Israel. ${ }^{29}$

Terutama dalam menghentikan program non - proliferasi senjata pemusnah massal di dunia. Namun, setiap presiden mempunyai cara tersendiri dan kebijakan luar negeri yang berbeda untuk mencapai kepentingan Amerika Serikat tersebut. Salah satunya adalah kebijakan yang dipilih presiden Amerika Serikat dalam memandang program nuklir Iran. Pola kebijakan Amerika Serikat dipandang dinamis dalam menentukan sikap

${ }^{27}$ Glenn Hastedt, Encyclopedia of American Foreign Policy, (New York: Facts On File, Inc, 2004), hal. VII

${ }^{28}$ CRF, War in Iraq, https://www.crf-usa.org/war-in-iraq/foreign-policy.html, diakses 5 November 2019

${ }^{29}$ Pat Paterson, Op. Cit., hal. 26 
untuk menyelesaikan permasalahan nuklir Iran sesuai dengan Presiden yang sedang berkuasa di Negara tersebut.

\section{Politik Luar Negeri Amerika Serikat pada masa pemerintahan Donald Trump}

Dalam pidato pemilihannya, Trump berjanji untuk menjadikan Amerika Serikat hebat kembali atau semboyan yang sering dikeluarkan adalah "make America great again. ${ }^{30}$ Trump berupaya untuk memajukan kembali peran Amerika Serikat di dunia. Kebijakan yang dikeluarkan presiden Trump antara lain memerintahkan pembekuan bagi imigrasi dari tujuh negara mayoritas muslim, mengusulkan kenaikan anggaran militer Amerika Serikat, memerintahkan lebih banyak pasukan ke Suriah, dan mengundurkan diri dari perjanjian yang tidak sesuai dengan kepentingan nasional Amerika Serikat.

Kebijakan luar negeri Trump memiliki perubahan yang signifikan dibandingkan dengan kebijakan presiden sebelumnya, Barack Obama. Salah satu kebijakan Amerika Serikat yang menarik pada masa Donald Trump adalah sikap Amerika Serikat terhadap kawasan Timur Tengah. Hal ini sesuai dengan janji Donald Trump selama kampanye tahun 2016 untuk melakukan pendekatan yang berbeda terhadap kawasan Timur Tengah. Presiden Trump berusaha untuk meningkatkan hubungan dengan Israel dan Arab Saudi dan melakukan isolasi terhadap Iran. Iran merupakan fokus utama pemerintahan Trump dimana strategi keamanan nasional Amerika Serikat sering menyebutkan bahwa Iran digambarkan sebagai daftar prioritas utama Amerika Serikat dalam mencegah dominasi kekuatan yang bertentangan dengannya. ${ }^{31}$

Presiden Donald Trump secara sepihak keluar dari kesepakatan program nuklir Iran atau Joint Comprehensive Plan of Action (JCPOA) yang dibuat oleh Presiden Barack Obama. Menurut Trump, kesepakatan tersebut membuat rendah Amerika Serikat di mata dunia dan kesepakatan tersebut tidak akan mencegah nuklir Iran berkembang. Trump mengubah kebijakan pada program nuklir Iran yang dapat dilihat dari beberapa poin, yakni

\footnotetext{
${ }^{30}$ Pat Paterson, Op. Cit., hal. 40

${ }^{31}$ Jack Thompson, Trump's Middle East Policy, Center for Security Studies, No.
} 233, 2018, hal. 2, https://css.ethz.ch/content/dam/ethz/special-interest/gess/cis/center-forsecurities-studies/pdfs/CSSAnalyse233-EN.pdf, diakses 7 November 2019 
memaksa Iran untuk melakukan negosiasi ulang, dan menolak Iran untuk mengembangkan kemampuannya dan tidak ikut campur dalam permasalahan yang ada di kawasannya.

Pada pidato Sekretaris Negara Amerika Serikat tanggal 21 Mei 2018, Pompeo mengumumkan strategi Amerika Serikat untuk menekan Iran melalui sanksi. ${ }^{32}$ Sanksi tersebut berupa pembatasan Iran untuk mengekspor minyak sehingga dapat memukul perekonomian Iran. Selain itu, Amerika Serikat juga memberikan sanksi kepada Negara - negara yang akan mengimpor minyaknya dari Iran. Iran sangat bergantung pada ekspor minyak dan Amerika Serikat berharap sanksi tersebut akan membuat negara Iran terpuruk

Trump memberikan tekanan agar Iran dapat menerima kesepakatan baru yang lebih komprehensif. Trump menginginkan agar kesepakatan tersebut juga berisi tentang rudal balistik, aktivitas nuklir Iran setelah 2025 dan peran Iran di Suriah. Dengan demikian, kesepakatan itu tidak hanya berlaku sampai 15 tahun dan setelahnya Iran dapat mengembangkan tenaga nuklirnya, tetapi juga tentang masa depan nuklir Iran. Trump menjelaskan bahwa tindakan yang dilakukan Amerika Serikat bukan untuk menimbulkan peperangan, tetapi membicarakan tentang negosiasi kembali perjanjian nuklir Iran.

\section{Program Nuklir Iran}

Program nuklir Iran tidak lepas dari peran Amerika Serikat. Pada awalnya, nuklir Iran mendapat dukungan dan bantuan dari negara Amerika Serikat dan hubungan kedua negara dikatakan harmonis. Namun, pada saat terjadinya revolusi Islam di dalam negara Iran yang membuat bergantinya rezim di Iran, hubungan kedua negara tersebut menjadi tidak harmonis dan program nuklir Iran tidak lagi mendapat dukungan dari Amerika Serikat. Amerika Serikat khawatir bahwa nuklir Iran dikembangkan untuk membangun teknologi senjata nuklir sehingga Amerika Serikat merasa terancam kepentingan dan keamanannya di kawasan Timur Tengah.

Iran menekankan program nuklir nya hanya untuk tujuan damai yaitu sumber energi alternatif sebagai cadangan minyak Iran. Hal ini dikarenakan

${ }^{32}$ CRS Report, Iran: Internal Politics and U.S. Policy and Options, Congressional Research Service 2019, hal. 22 
banyak Negara - negara yang mengambil minyak dari Iran sehingga cadangan minyaknya akan dapat menipis. Oleh karena itu, Iran berusaha untuk meyakinkan kepada dunia bahwa nuklirnya tidak diperuntukan sebagai alat ancaman di kawasan Timur Tengah dan Iran meminta bantuan terhadap Negara - negara yang mengambil minyaknya ke Negaranya.

Presiden mempunyai peran yang penting dalam membuat kebijakan luar negeri Iran, terutama dalam hal nuklir. Setiap presiden Iran mempunyai cara tersendiri dalam berupaya untuk mengembangkan tenaga nuklirnya. Terdapat presiden yang pro dan juga kontra terhadap bantuan dari luar untuk mengembangkan nuklirnya.

\section{Kebijakan Luar Negeri Amerika Serikat dalam Program Nuklir Iran}

Nuklir Iran dianggap sebagai ancaman terhadap stabilitas di kawasan Timur Tengah. Hubungan Amerika Serikat dengan Iran sering mengalami pasang surut dan bergejolak sejak terjadinya Revolusi Islam di Iran pada tahun 1979. Karena itu Iran menjadi perhatian utama pemerintah Amerika Serikat. Hal ini dilihat dari Strategi Keamanan Nasional Amerika Serikat yang menyebutkan Iran sebanyak 17 kali dan menjadi daftar prioritas utama pencegahan dominasi kekuatan di dunia. Presiden Donald Trump mengubah kebijakan luar negerinya dari presiden sebelumnya, Barack Obama. Sejak masa kampanye, Trump sudah mempunyai pendekatan yang berbeda.

Trump bertekad untuk merubah kebijakan luar negeri mantan presiden Obama yang dianggap lemah, seperti dalam menanggapi kesepakatan nuklir dengan Iran. Pada akhirnya, presiden Trump memutuskan untuk keluar dari kesepakatan nuklir atau Joint Comprehensive Plan of Action (JCPOA) pada tanggal 8 Mei 2018 dan memberlakukan kembali sanksi terhadap Iran. Steven Mnuchin, Menteri Keuangan Amerika Serikat, mengumumkan bahwa Iran akan diberikan sanksi tambahan walaupun sekutu Amerika Serikat lainnya tidak setuju. ${ }^{33}$ Dengan demikian, Trump melakukan "maximum pressure" agar Iran dapat mengikuti keinginan dari Amerika Serikat.Pertama, Amerika Serikat secara sepihak menarik diri dari

${ }^{33}$ Mohammed Cherkaoui, Trump's Withdrawal from the Iran Nuclear Deal: Security or Economics?, Al Jazeera Centre for Studies, 2018, hal. 2, https://studies.aljazeera.net/sites/default/files/articles/reports/documents/d6a4c71882da438e 9de76152c7e3a8dc_100.pdf, diakses 26 Desember 2019 
kesekapatan nuklir pada tanggal 8 Mei 2018. ${ }^{34}$ Trump memandang kesepakatan tersebut sebagai kesepakatan yang buruk dan Amerika Serikat dapat dianggap lemah oleh Negara lain.Maximum Pressure diberikan Trump untuk menekan Iran melakukan negosiasi dengan membuat kesepakatan nuklir yang baru. ${ }^{35}$

\section{Keluarnya Amerika Serikat dari Kesepakatan Nuklir Iran atau Joint Comprehensive Plan of Action (JCPOA)}

Selama pemilihan Presiden, Donald Trump sudah melakukan kritik terhadap kesepakatan yang berisi pembatasan produksi uranium Iran dan menyusun ulang reaktor airnya agar tidak dapat memproduksi plutonium, dengan imbalan dicabutnya sanksi terhadap Iran.

Ketika Trump menjabat sebagai presiden Amerika Serikat pada tanggal 8 Mei 2018, Trump secara sepihak keluar dari kesepakatan nuklir Iran. Terdapat dua faktor yang mempengaruhi pemikiran garis keras Trump dalam kebijakannya terhadap Iran. Pertama, bagi kaum konservatif, kesepakatan nuklir Iran yang dibuat oleh presiden Obama merupakan kebijakan luar negeri Amerika Serikat yang lemah. Kedua, Trump menekan keterlibatan Iran di Suriah serta dukungannya terhadap Hamas dan Hizbullah.36

Sebelumnya, pada Januari 2018, Trump menuntut untuk mengubah Undang-Undang baru tentang JCPOA. Selain itu, Trump juga menginginkan amandemen Iran Nuclear Agreement Review Act (INARA), antara lain : ${ }^{37}$

- Menuntut agar Iran mengizinkan inspeksi di semua lokasi oleh Inspektur Internasional dari IAEA;

\footnotetext{
${ }^{34}$ Noviyanti, Polemik Perubahan Kebijakan Amerika Serikat dalam Kesepakatan The Joint Comprehensive Plan of Action (JCPOA) Nuklir Iran, LIPI, 2019.http://www.politik.lipi.go.id/kolom/kolom-1/politik-internasional/1288-polemikperubahan-kebijakan-amerika-serikat-dalam-kesepakatan-the-joint-comprehensvie-plan-ofaction-jcpoa-nuklir-iran, diakses 3 Januari 2020

${ }^{35}$ France 24 , Iran answers Trump's maximum pressure with maximum resistance, 8 November 2019, https://www.france24.com/en/20191108-iran-answers-trump-s-maximumpressure-with-maximum-resistance, diakses 26 Desember 2019

${ }^{36}$ Jack Thompson dan Oliver Thränert, Trump Preparing to End Iran Nuke Deal, Center for Security Studies, Vol. 5 No. 5, 2017, hal. 2, ttps://css.ethz.ch/en/services/digitallibrary/articles/article.html/fe01edc1-abc5-4367-b208-ee198d566b43/pdf, diakses 26 Desember 2019

${ }^{37}$ Paul K Kerr dan Kenneth Katzman, Iran Nuclear Agreement and U.S. Exit, Congressional Research Service, 2018, hal. 23
} 
- Memastikan Iran untuk tidak menghasilkan bahan untuk pembuatan senjata nuklir dalam waktu kurang dari satu tahun;

- Menerapkan kembali sanksi dari Amerika Serikat apabila Iran tidak mematuhi kriteria kesepakatan yang baru;

- Apabila Iran mengembangkan senjata nuklir dan rudal jarak jauh akan dikenakan sanksi berat.

Trump menekan untuk menegosiasikan kembali Joint Comprehensive Plan of Action (JCPOA) untuk mengatasi kekhawatiran Amerika Serikat akan masa depan program nuklir Iran dengan poin - poin antara lain $:^{38}$

- Iran memberitahukan dengan lengkap kepada IAEA tentang situs nuklir dan militernya

- Iran harus menghentikan pengayaan uranium dan tidak melakukan pemprosesan ulang plutonium

- Iran harus menyediakan akses IAEA tanpa pengecualian di seluruh lokasi

- Iran harus mengakhiri pengembangan sistem nuklirnya

- Iran harus melepaskan semua warga Amerika Serikat serta warga dari sekutunya yang ditahan atas tuduhan palsu

- Iran harus mengakhiri dukungan kepada kelompok teroris Timur Tengah, seperti Lebanon, Hizbullah, Hamas dan Jihad Palestina

- Iran harus menghormati kedaulatan Irak dan mengizinkannya untuk melucuti senjata, demobilisasi dan reintegrasi dengan milisi Syiah

- Iran harus mengakhiri dukungan militernya untuk milisi Houthi demi penyelesaian konflik di Yaman

- Iran harus menarik semua pasukannya di Suriah

- Iran harus mengakhiri dukungan untuk Taliban

- Iran harus mengakhiri pasukan IRGC (Islamic Revolutionary Guard Corps) yang memberi dukungan terhadap teroris dan militan di seluruh dunia

- Terakhir, Iran harus mengakhiri perilaku mengancamnya kepada Negara tetangga, seperti ancaman penembakan rudal ke Israel, Arab Saudi dan Uni Emirat Arab.

\footnotetext{
${ }^{38}$ Paul K Kerr dan Kenneth Katzman, Op. Cit, hal. 24-25
} 
Pada intinya, Trump menganggap bahwa kesepakatan nuklir Iran tahun 2015 merupakan kesepakatan terburuk yang pernah ada. Hal ini dikarenakan tidak adanya larangan program rudal balistik Iran, larangan Iran untuk mendukung Hizbullah dan Hamas, dan tidak menyebutkan aktivitas nuklir Iran setelah tahun 2025. Dengan demikian, Amerika Serikat ingin melakukan negosiasi ulang sesuai dengan poin - poin diatas. Iran merasa bahwa persyaratan yang diajukan oleh Trump tidak masuk akal dikarenakan Iran merasa bahwa masalah pengayaan uranium tidak melanggar pakta nonproliferasi dan Iran juga berhak akan itu. Semua aktivitas Iran dibawah pengawasan IAEA dan dengan cara yang transparan.

Akibatnya, Trump memberikan Sanksi kepada Iran dengan menerapkan adalah "maximum pressure" untuk menekan Iran melakukan negosiasi ulang kesepakatan nuklir dan menghilangkan kekhawatiran Amerika Serikat akan dominasi Iran di kawasan Timur Tengah. Amerika Serikat telah menerapkan sanksi terhadap Iran sejak pemerintahan Shah digulingkan pada tahun 1979. Amerika Serikat menjatuhkan sanksi terhadap Iran secara bertahap, antara lain : ${ }^{39}$

1. Larangan perdagangan dan investasi dengan Iran

2. Sanksi sektor energi Iran

3. Sanksi atas pemberian senjata pemusnah massal, rudal dan transfer senjata konvensional terhadap Iran untuk mencegah Iran memperoleh teknologi atau peralatan yang dapat digunakan untuk pembuatan senjata pemusnah massal dan larangan transfer senjata konvensional dikarenakan Iran memberi dukungan kelompok-kelompok teroris di Timur Tengah ${ }^{40}$

4. Sanksi terhadap sektor otomotif Iran, perdagangan rial, dan batu mulia

5. Sanksi keuangan/perbankan untuk menutup akses Iran dari sistem perbankan internasional, dan memberikan sanksi bagi bank asing yang melakukan transaksi dengan Iran

6. Sanksi atas kejahatan dunia maya dan kejahatan transnasional Iran yang membuat perusahaan asing yang membantu Iran akan diberikan sanksi oleh Amerika Serikat.

Setelah itu, Trump memberlakukan kembali sanksi sekunder kepada Iran untuk melemahkan perekonomian Iran. Nilai mata uang Iran menurun

\footnotetext{
${ }^{39}$ CRS Report, 2018, Iran Sanctions, Congressional Research Service, hal. 7-34

${ }^{40}$ CRS Report, Op. Cit. hal. 7-34
} 
sehingga menimbulkan keresahan warga Iran. Dengan diberlakukannya sanksi tersebut membuat Iran tidak mengalami kemajuan ekonomi. Dengan demikian, Iran mengadopsi strategi konfrontasi dengan memulai kembali pengayaan uraniumnya dan melanggar beberapa kesepakatan nuklirnya. Trump meyakini satu-satunya cara untuk menekan Iran untuk menerima kesepakatan nuklir baru adalah dengan memberikan sanksi. Hal ini kemudian membuat hubungan Amerika Serikat dan Iran menjadi tidak harmonis dan meningkatkan tensi geopolitik di Timur Tengah.

\section{Kesimpulan}

Trump memberlakukan kebijakan luar negeri yang baru terhadap Iran dengan menerapkan maximum pressure terhadap Iran. Maximum Pressure diberikan Trump untuk menekan Iran melakukan negosiasi dengan membuat kesepakatan nuklir yang baru. Trump menginginkan untuk melakukan perubahan terhadap isi dari kesepakatan karena dapat membuat Iran lebih mengembangkan program nuklirnya. Kedua, memberlakukan kembali sanksi dan memberlakukan sanksi tambahan terhadap Iran. Sanksi dilakukan oleh Amerika Serikat dalam menerapkan maksimum pressure untuk mengubah tingkah laku Iran.

\section{Daftar Pustaka}

BBC News, Amerika Serikat terapkan 'sanksi terberat', apakah Iran bisa tumbang?, 5 November 2018, https://www.bbc.com/indonesia/dunia 46093285, diakses 5 September 2019

BBC News, Iran nuclear crisis in 300 words, September 2019.https://www.bbc.com/news/world - middle - east - 48201138, diakses 4 September 2019

Behrang,Fahimeh, U.S Foreign Policy Interests and Iran's Nuclear Program, tesis, Canada, University of Saskatchewan, 2012, hal. 12

Cherkaoui,Mohammed, Trump's Withdrawal from the Iran Nuclear Deal: Security or Economics, Aljazeera Centre for Studies, 2018, hal. 4, https://studies.aljazeera.net/sites/default/files/articles/reports/documen ts/d6a4c71882da438e9de76152c7e3a8dc 100.pdf, diakses 5 September 2019

Cordesman, Anthony H. dan Khalid R. Al - Rodhan, Iranian Nuclear Weapons? The Uncertain Nature of Iran's Nuclear Programs, Center 
18 | FOKUS : Jurnal Kajian Keislaman dan Kemasyarakatan Vol. 5, No. 1, 2020

for Strategic and International Studies, 2006, hal. 13. https://csis prod.s3.amazonaws.com/s3fs

public/legacy_files/files/media/csis/pubs/060412_iran_uncertainty.pd f, diakses 4 September 2019

CNN, Polemik Pakta Nuklir Iran: Optimisme yang Terancam Kandas, 9 Mei 2019, https://www.cnnindonesia.com/internasional/20190509134640 - 120 - 393376/polemik - pakta - nuklir - iran - optimisme - yang terancam - kandas, diakses 5 September 2019

CRF, War in Iraq, https://www.crf - usa.org/war - in - iraq/foreign policy.html, diakses 5 November 2019

Croft, A, Iran Nuclear Talks Show Progress, Western Diplomat Says, Reuters, 2013. https://www.reuters.com/article/us - iran - nuclear talks/iran - nuclear - talks - constructive - western - diplomat - says - idUSBRE91R1IO20130228, diakses 4 September 2019

CRS Report, Iran: Internal Politics and U.S. Policy and Options, Congressional Research Service 2019, hal. 22

DonaldJTrump.com, Donald Trump Foreign Policy Speech

France 24, Iran answers Trump's maximum pressure with maximum $\begin{array}{llll}\text { resistance, } & 8 & \text { November }\end{array}$ https://www.france24.com/en/20191108 - iran - answers - trump - s - maximum - pressure - with - maximum - resistance, diakses 26 Desember 2019

Hastedt, Glenn, Encyclopedia of American Foreign Policy, (New York: Facts On File, Inc, 2004), hal. VII

Kerr,Paul K dan Kenneth Katzman, Iran Nuclear Agreement and U.S. Exit, Congressional Research Service, 2018, hal. 23

Levy,Jack S, "Qualitative Methods in International Relations", dalam Harvey, Frank P. \& Brecher, Michael (ed.), Evaluating Methodology in International Studies, (Ann Arbor: The University of Michigan Press, 2002), hal. 131

Mas'oed, Mochtar, Ilmu Hubungan Internasional: Disiplin dan Metodologi, (Jakarta: LP3ES, 1994), hal. 184 
Nincic, Miroslav, The National Interest and Its Interpretation, The review of Politics Vol. 61 No. 1, 1999, hal. 32

Noviyanti, Polemik Perubahan Kebijakan Amerika Serikat dalam Kesepakatan The Joint Comprehensive Plan of Action (JCPOA) Nuklir Iran, LIPI, 2019.http://www.politik.lipi.go.id/kolom/kolom 1/politik - internasional/1288 - polemik - perubahan - kebijakan amerika - serikat - dalam - kesepakatan - the - joint comprehensvie - plan - of - action - jcpoa - nuklir - iran, diakses 4 September 2019

Perwita, A. A dan Y. M Yani, Pengantar Ilmu Hubungan Internasional, (Bandung: Remaja Rosdakarya, 2005), hal. 51

Plano, J. C dan R Olton, Kamus Hubungan Internasional, (Bandung: Abardin, 1999), hal. 5

Pujayanti, Adirini, Sengketa Nuklir Iran - Amerika Serikat, Puslit BKD, 2019 ,

hal.

7,https://berkas.dpr.go.id/puslit/files/info_singkat/Info\%20Singkat -

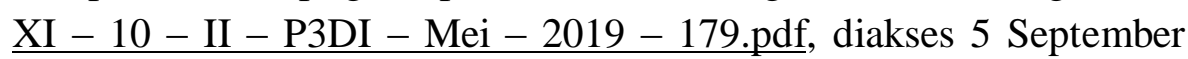
2019

Rizky,Resty Meiva, Perubahan Kebijakan Nuklir Iran Di Era Pemerintahan Hassan Rouhani, Jurnal Mahasiswa Bidang Ilmu Sosial dan Ilmu Politik 2, Riau, Universitas Riau, 2013, hal. 6

Sterio,Milena, President Obama's Legacy: The Iran Nuclear Agreement, Case Western Reserve Journal of International Law Vol. 48, 2016, hal. 74 75 ,

https://scholarlycommons.law.case.edu/cgi/viewcontent.cgi?article=2 236\&context=jil, diakses 5 September 2019

Thompson, Jack dan Oliver Thränert, Trump Preparing to End Iran Nuke Deal, Center for Security Studies, Vol. 5 No. 5, 2017, hal. 2, https://css.ethz.ch/en/services/digital library/articles/article.html/fe01edc1 - abc5 - 4367 - b208 ee198d566b43/pdf, diakses 26 Desember 2019

Thompson, Jack, Trump's Middle East Policy, Center for Security Studies, No. 233, 2018, hal. 2, 
20 | FOKUS : Jurnal Kajian Keislaman dan Kemasyarakatan Vol. 5, No. 1, 2020

https://css.ethz.ch/content/dam/ethz/special - interest/gess/cis/center - for securities - studies/pdfs/CSSAnalyse233 - EN.pdf, diakses 7 November 2019

VOA, AS Siap Terapkan Sanksi Baru terhadap Iran, 24 Juni 2019, https://www.voaindonesia.com/a/as - terapkan - sanksi - baru terhadap - iran/4971499.html, diakses 5 September 2019 